\title{
Post-Traumatic Stress Disorder
}




\section{Post-Traumatic \\ STRESS Disorder}

\section{Basic SCIENCE AND}

Clinical Practice

Edited by

Priyattam J. Shiromani

Harvard Medical School, Department of Neurology, VA Boston Healthcare System, West Roxbury, MA

\section{Terence M. Keane}

National Center for Post-Traumatic Stress Disorder,

VA Boston Healthcare System, Boston MA

\section{Joseph E. LeDouX}

New York University, Center for Neural Science, New York, NY

藻 Humana Press 


\section{Editors}

Priyattam J. Shiromani

Harvard Medical School

Department of Neurology

VA Boston Healthcare System

West Roxbury, MA

\section{Joseph E. LeDoux}

New York University,

Center for Neural Science,

New York, NY
Terence M. Keane

National Center for Post-Traumatic

Stress Disorder

VA Boston Healthcare System

Boston MA

ISBN 978-1-60327-328-2

e-ISBN 978-1-60327-329-9

DOI: $10.1007 / 978-1-60327-329-9$

Library of Congress Control Number: 2008942054

(C) Humana Press, a part of Springer Science + Business Media, LLC 2009

All rights reserved. This work may not be translated or copied in whole or in part without the written permission of the publisher (Humana Press, c/o Springer Science + Business Media, LLC, 233 Spring Street, New York, NY 10013, USA), except for brief excerpts in connection with reviews or scholarly analysis. Use in connection with any form of information storage and retrieval, electronic adaptation, computer software, or by similar or dissimilar methodology now known or hereafter developed is forbidden.

The use in this publication of trade names, trademarks, service marks, and similar terms, even if they are not identified as such, is not to be taken as an expression of opinion as to whether or not they are subject to proprietary rights.

While the advice and information in this book are believed to be true and accurate at the date of going to press, neither the authors nor the editors nor the publisher can accept any legal responsibility for any errors or omissions that may be made. The publisher makes no warranty, express or implied, with respect to the material contained herein.

Printed on acid-free paper

springer.com 


\section{Preface}

Post-traumatic stress disorder or PTSD is a psychiatric condition that can occur in anyone who has experienced a life-threatening or violent event. The trauma can be due to war, terrorism, torture, natural disasters, accidents, violence, or rape. PTSD was once associated exclusively with military service and characterized by the terms "shell shock" and "battle fatigue." However, now it is recognized that PTSD can occur in any traumatic situation and can afflict children as well as adults. Studies across cultures, languages, and races suggest that PTSD is a universal response to exposure to traumatic events.

In the U.S. population, the prevalence rate of PTSD is approximately $8 \%$, with the rate for women more than twice that for men (1). In the aftermath of Hurricane Katrina, the prevalence of PTSD in the New Orleans metro area (hardest hit by the hurricane) was $30.3 \%$ compared to $12.5 \%$ in the remainder of the hurricane area (2). Among U.S. military personnel, a study (3) found that during the 1991 Gulf War symptoms of PTSD were evident in $6.2 \%$ of the deployed troops versus $1.1 \%$ of the nondeployed peers. Importantly, 10 years later the rate of PTSD among deployed veterans (Operation Enduring Freedom-Operation Iraqi Freedom; OEF-OIF) was three times higher than in the nondeployed peers. In the Iraq War, a U.S. Army study found that $12.9 \%$ of the soldiers suffered from PTSD (4). Not all individuals exposed to a lifethreatening event develop PTSD, indicating significant individual differences in coping with the stressful event. However, prior history of trauma may increase the risk for PTSD (5), suggesting an additive effect of stress.

The brain's response to trauma and stress, also termed the "fight-or-flight" response, was first described by Walter Cannon in 1915 (6). Its purpose is to mobilize the body to action and protect us from danger. The cascade of chemicals unleashed during a fight-or-flight response acts on specific brain regions, in particular the hippocampus and amygdala, which are parts of the limbic system related to emotion, memory, and cognition. The amygdala is especially vulnerable because it is here that a fearful association of the event is processed and stored.

Individuals with PTSD have memories of the event that they relive again and again (i.e., flashbacks, nightmares, preoccupation with thoughts or images of the events of war); they avoid people and places associated with the trauma, becoming distressed at cues or reminders of the experience (e.g., the anniversary of the event); and they are hyperaroused (difficulty sleeping, trouble concentrating, hypervigilant). 
In the past few years, there has been a tremendous growth in our understanding of PTSD. Relevant brain areas have been identified; there are animal models to study the disease; there are sound evaluation methods; and large-scale clinical trials are under way to examine the effectiveness of psychological and pharmacological treatments. In this text, we have invited experts to review the current state of knowledge regarding PTSD, including treatment strategies, both pharmacological and psychological. The collection of reviews in this book covers epidemiological findings, neurobiology and neurophysiology, brain imaging, and treatment strategies.

We would like to thank Richard Lansing at Humana Press for recognizing the need for this book, Amanda Quinn and Joseph Albert André for assistance with the publication process.

P. J. Shiromani

Terence M. Keane

Joseph LeDoux

\section{REFERENCES}

1. Kessler, R. C., Sonnega, A., Bromet, E., Hughes, M., and Nelson, C. B. (1995) Posttraumatic stress disorder in the National Comorbidity Survey. Arch Gen Psychiatry 52, $1048-1060$.

2. Galea, S., Brewin, C. R., Gruber, M., Jones, R. T., King, D. W., King, L. A., McNally, R. J., Ursano, R. J., Petukhova, M., and Kessler, R. C. (2007) Exposure to hurricanerelated stressors and mental illness after Hurricane Katrina. Arch Gen Psychiatry 64(12), 1427-1434.

3. Toomey, R., Kang, H. K., Karlinsky, J., Baker, D. G., Vasterling, J. J., Alpern, R., Reda, D. J., Henderson, W. G., Murphy, F. M., Eisen, S. A. (2007) Mental health of US Gulf War veterans 10 years after the war. Br J Psychiatry 190, 385-393.

4. Hoge, C. W., Castro, C. A., Messer, S. C., McGurk, D., Cotting, D. I., and Koffman, R. L. (2004) Combat duty in Iraq and Afghanistan, mental health problems, and barriers to care. N Engl J Med 351, 13-22.

5. King, D. W., King, L. A., Foy, D. W., and Gudanowski, D. M. (1996) Prewar factors in combat-related posttraumatic stress disorder: structural equation modeling with a national sample of female and male Vietnam veterans. J Consult Clin Psychol 64, 520-531.

6. Cannon, W. (1915) Bodily Changes in Pain, Hunger, Fear and Rage: An Account of Recent Researches into the Function of Emotional Excitement. Appleton.New York: 


\section{About the Editors}

P. J. Shiromani, Ph.D., is an associate professor of neurology at Harvard Medical School and senior research scientist at the VA Boston Healthcare System, where he is the director of the Molecular Sleep Laboratory. Dr. Shiromani's research identifies the neural circuitry underlying sleep and wakefulness and how the brain shifts between states of consciousness. He has pioneered the use of molecular tools to identify key neurons regulating sleep. His current research effort uses gene transfer to rescue the neurodegenerative sleep disorder narcolepsy. In recognition of his research, he has received the Young Investigator Award from the Sleep Research Society. He is the author of more than 100 research articles in leading scientific journals. His research has been supported by the National Institutes of Health (NIH) and by the Veterans Administration. He has served as chair of an NIH review group and as a regular member of several NIH review groups. He was the first editor of the Sleep Research Society Bulletin.

Terence M. Keane, Ph.D., is associate chief of staff for research and development, VA Boston Healthcare System; director, National Center for PTSD, Behavioral Sciences Division; professor and vice chair of research and psychiatry, Boston University School of Medicine. He is recognized internationally as a leading expert on trauma and PTSD, authoring numerous books and research articles in peer-reviewed journals.

Joseph E. LeDoux, M.D., is university professor and Henry and Lucy Moses Professor of Science, New York University; director, Center for the Neuroscience of Fear and Anxiety; and director, Emotional Brain Institute. He is the author of hundreds of research articles in scholarly journals and books (The Emotional Brain, Simon \& Schuster; and Synaptic Self, Viking Press). LeDoux's work focuses on the study of the neural basis of emotions, especially fear and anxiety. Central to emotional processing is the amygdala, a brain area that LeDoux and his collaborators study extensively. Using an array of methods, including neuroanatomical, electrophysiological, neurochemical, molecular, and behavioral approaches, he has contributed to the understanding of emotional learning and memory. For more information, visit www.cns.nyu.edu/ledoux. Over the course of his career, LeDoux has received a number of awards, including the Fyssen Foundation International Prize, the Hoch Award, the Jean-Louis Signoret Prize, and consecutive MERIT Awards and Research Scientist Awards from the American National Institute of Mental Health. LeDoux sits on the editorial board of several journals and has given the Society for Neuroscience Presidential Lecture. He is a Fellow of the American Association for the Advancement 
of Science, a Fellow of the New York Academy of Sciences, and a Fellow of the American Academy of Arts and Sciences. LeDoux is also a member of the Amygdaloids, a band of scientists who play original songs about mind and brain and mental disorders, the lyrics of which are often inspired by his research. Since the Amygdaloids formed in 2006, they have played at Madison Square Garden, the John F. Kennedy Center, the 92nd Street Y, and numerous rock clubs in New York City. Their first CD, Heavy Mental, was released in 2007, and they are working on a second CD tentatively titled Brainstorm. Information about the band is available at www.cns.nyu.edu/ledoux/amygdaloids and at www.myspace.com/amygdaloids. 


\section{Contents}

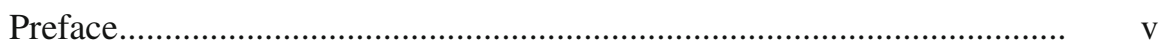

About the Editors ................................................................................... vii

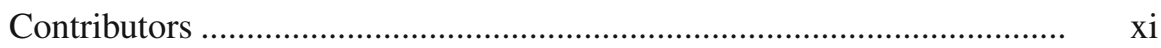

1 Post-Traumatic Stress Disorder: Definition, Prevalence, and Risk Factors

Terence M. Keane, Brian P. Marx, and Denise M. Sloan

Amygdala and Fear

2 The Amygdala and the Neural Pathways of Fear................................. 23 Jacek Debiec and Joseph LeDoux

3 Physiology of the Amygdala: Implications for PTSD

Donald G. Rainnie and Kerry J. Ressler

4 Counteracting Molecular Pathways Regulating the Reduction of Fear: Implications for the Treatment of Anxiety Diseases ... Andre Fischer and Li-Huei Tsai

5 Memory in PTSD:A Neurocognitive Approach Mieke Verfaellie and Jennifer J. Vasterling

Animal Models of Post-Traumatic Stress Disorder

6 Toward Animal Models of Post-Traumatic Stress Disorder Hagit Cohen and Gal Richter-Levin

7 PTSD: From Neurons to Networks

Rajnish P. Rao, Aparna Suvrathan, Melinda M. Miller, Bruce S. McEwen, and Sumantra Chattarji

Post-Traumatic Stress Disorder and Arousal

8 Arousal Neurons in the Brain ..

Priyattam J. Shiromani and Carlos Blanco-Centurion

9 Hyperarousal and Post-Traumatic Stress Disorder:

A Role for the Hypocretin System

Matt Carter and Luis de Lecea 
10 The Locus Coeruleus-Noradrenergic System and Stress:

Implications for Post-Traumatic Stress Disorder

Craig W. Berridge

11 Effect of Stress on Sleep and Its Relationship

to Post-Traumatic Stress Disorder.

L. D. Sanford and X. Tang

Stress Hormones in Post-Traumatic Stress Disorder

12 Stress Hormones and PTSD

Rachel Yehuda

13 Low Basal Cortisol and Startle Responding as Possible

Biomarkers of PTSD: The Influence of Internalizing and Externalizing Comorbidity ....

Mark W. Miller, Erika J. Wolf, Laura Fabricant, and Nathan Stein

Brain Imaging in Post-Traumatic Stress Disorder

14 Functional Neuroimaging in Post-Traumatic Stress Disorder Israel Liberzon and Sarah N. Garfinkel

15 The Amygdala in Post-Traumatic Stress Disorder.

Lisa M. Shin

Treatment Strategies

16 Pharmacologic Treatment of PTSD.

Murray A. Raskind

17 Guided Imagery as a Therapeutic Tool in Post-Traumatic

Stress Disorder

Jennifer L. Strauss, Patrick S. Calhoun, and Christine E. Marx

18 Virtual Reality Exposure Therapy for Combat-Related PTSD

Albert Rizzo, Greg Reger, Greg Gahm, JoAnn Difede, and Barbara $O$. Rothbaum

Index 


\section{Contributors}

Craig W. Berridge, PhD • Department of Psychology, University of Wisconsin-Madison, 1202 West Johnson Street, Madison, WI 53706

Carlos Blanco-Centurion, PhD • Department of Neurology, VA Boston Healthcare System and Harvard Medical School, 1400 Veterans of Foreign Wars Parkway, West Roxbury, MA 02132

Patrick S. Calhoun, PhD • 508 Fulton Street, Mental Health Service Line (116A), Durham, North Carolina, 27705

Matt CARTER, BSc • Department of Psychiatry and Behavioral Sciences, Stanford University, 701B Welch Road, Palo Alto, CA 94304

Sumantra Chattarj, PhD • National Centre for Biological Sciences, Tata Institute of Fundamental Research, Bellary Road, Bangalore 560 065, India

Hagit Cohen, PhD • Beer-Sheva Mental Health Center, The State of Israel Ministry of Health, Anxiety and Stress Research Unit, Faculty of Health Sciences, Ben-Gurion University of the Negev, Beer-Sheva, 84170, Israel

JACEK DebIEc, MD, PHD • Center for Neural Science, New York University, 4 Washington Place, Room 809, New York, NY 10003

LuIS DE LECEA, PHD • Department of Psychiatry and Behavioral Sciences, Stanford University, 701B Welch Road, Palo Alto, CA 94304

JoAnn Difede, PhD • Weill Cornell Medical College, New York Presbyterian Hospital, 525 East 68th Street, Box 200, New York, NY 10021

Laura Fabricant, BA • National Center for PTSD (116B-2), VA Boston Healthcare System, 150 South Huntington Avenue, Boston, MA 02130

ANDRE FISCHER, PHD • European Neuroscience Institute, Laboratory for Aging and Cognitive Diseases, Grisebach Strasse 5, D-37077 Goettingen, Germany

Greg Gahm, PhD • Telehealth and Technology, Madigan Army Medical Center, Madigan Annex, Building 9933A, Fort Lewis, WA 98431

SARAh N. GARFINKeL, PHD • Department of Psychiatry, University of Michigan, Rachel Upjohn Building, Room 2753, 4250 Plymouth Road, Box 5765, Ann Arbor, MI 48109-2700

Terence M. Keane, PhD • National Center for PTSD (116B-2), VA Boston Healthcare System, 150 South Huntington Avenue, Boston, MA 02130

Joseph LeDoux, MD • Center for Neural Science, New York University, 4 Washington Place, Room 809, New York, NY 10003 
IsRael Liberzon, MD • Department of Psychiatry, University of Michigan, Rachel Upjohn Building, Room 2753, 4250 Plymouth Road, Box 5765, Ann Arbor, MI 48109-2700

Brian P. MARX, PhD • National Center for PTSD (116B-2), VA Boston Healthcare System, 150 South Huntington Avenue, Boston, MA 02130

Christine E. Marx, MD, MA • 508 Fulton Street, Mental Health Service Line (116A), Durham, NC 27705

Bruce S. McEwen, PHD • Laboratory of Neuroendocrinology, Rockefeller University, 1230 York Ave, New York, NY 10065

Mark W. Miller, PhD • National Center for PTSD (116B-2), VA Boston Healthcare System, 150 South Huntington Avenue, Boston, MA 02130

Melinda M. Miller • Rockefeller University, 1230 York Ave, New York, NY 10065

Donald G. Rainnie, PhD • Emory University, Department of Psychiatry, Yerkes National Primate Center, 954 Gatewood Road, Atlanta, GA 30329

Rajnish P. RAO, PHD • National Centre for Biological Sciences, Tata Institute of Fundamental Research, Bellary Road, Bangalore 560 065, India

Murray A. Raskind, MD • VA Puget Sound Health Care System, 1660 South Columbian Way, S116-6 East, Seattle, WA 98105

Greg Reger, PhD • Telehealth and Technology, Madigan Army Medical Center, Madigan Annex, Building 9933A, Fort Lewis, WA 98431

Kerry J. Ressler, MD, PhD • Yerkes Research Center, 954 Gatewood Drive, Atlanta, GA 30319

Gal Richter-LeVIn, PhD • The Institute for the Study of Affective Neuroscience (ISAN), The Brain and Behavior Research Center, Department of Psychology and Department of Neurobiology and Ethology, University of Haifa, Haifa, 31905 Israel

Albert Rizzo, PhD • USC Institute for Creative Technologies, Department of Psychiatry and School of Gerontology, 552 Crane Boulevard, Los Angeles, CA 90065

Barbara O. Rothbaum, PhD, ABPP • Emory University School of Medicine, 1256 Briarcliff Road, Building A, Third Floor, Atlanta, GA 30322

LARry D. SANFORD, PHD • Department of Pathology and Anatomy, Eastern Virginia Medical School, 700 Olney Road, Norfolk, VA 23501

LISA M. SHIN, PHD • Department of Psychology, Tufts University, 490 Boston Avenue, Medford, MA 02155

Priyattam J. Shiromani, PhD • Department of Neurology, VA Boston Healthcare System and Harvard Medical School, 1400 Veterans of Foreign Wars Parkway, West Roxbury, MA 02132 
Denise M. SloAn, PhD • National Center for PTSD (116B-2), VA Boston Healthcare System, 150 South Huntington Avenue, Boston, MA 02130

Nathan SteIn, PhD • National Center for PTSD (116B-2), VA Boston Healthcare System, 150 South Huntington Avenue, Boston, MA 02130

Jennifer L. Strauss, PhD • 508 Fulton Street, HSR\&D (152), Durham, NC 27705

Aparna Suvrathan • National Centre for Biological Sciences, Tata Institute of Fundamental Research, Bellary Road, Bangalore 560 065, India

Xiangdong TAng, PHD - Department of Pathology and Anatomy, Eastern Virginia Medical School, P.O. Box 1980, 700 Olney Road, Norfolk, VA 23501

Li-Huei Tsai, MD, PHD • Howard Hughes Medical Institute, Picower Institute for Learning and Memory, Department of Brain and Cognitive Sciences, MIT, 46 Vassar Street, Cambridge, MA 02139

Jennifer J. VAsterling, PhD • Psychology Service (116B), VA Boston Healthcare System, 150 South Huntington Avenue, Boston, MA 02130

MieKe Verfaellie, PhD • Memory Disorders Research Center (151A), VA Boston Healthcare System, 150 South Huntington Avenue, Boston, MA 02130

ERIKA J. WoLF, MA • National Center for PTSD (116B-2), VA Boston Healthcare System, 150 South Huntington Avenue, Boston, MA 02130

Rachel Yehuda, PhD • James J. Peters Veterans Affairs Medical Center, 130 West Kingsbridge Road, 526 OOMH PTSD 116-A, Bronx, NY 10468 